\title{
INTERESSES E INSTITUIÇÕES NA POLÍTICA DE SAÚDE*
}

\author{
Vera Schattan P. Coelho
}

Uma das grandes dificuldades enfrentadas por aqueles que procuram definir uma distribuição socialmente mais adequada de recursos na área de saúde é conciliar justiça e eficiência. Basta lembrar que toda vez que alguém no Ministério da Saúde ou nos organismos internacionais defende a rápida expansão da medicina preventiva e dos serviços clínicos essenciais em detrimento de uma medicina mais complexa ou, então, uma política de financiamento baseada em critérios de custo-efetividade, há,imediatamente, quem reconheça por trás da proposta o velho tecnocrata, aquele ser que, ao defender uma distribuição eficiente dos recursos públicos, se esquece, por exemplo, do doente pobre que será condenado à morte se precisar de um tratamento mais complexo. $\mathrm{O}$ difícil é que por mais que tentemos escolher entre justiça e eficiência, somos invariavelmente tomados pela certeza de que os argumentos a favor de qualquer um desses critérios são mais fortes do que desejaríamos.

Afinal, como deixar de reconhecer que o doente em estado mais grave deve ter prioridade em receber tratamento médico mesmo nos casos em que se sabe serem pequenas suas chances de pleno restabelecimento? Ou, então, como levar em conta critérios como idade ou escolaridade na escolha do paciente que receberá certos tratamentos caros? Em situações como essas, afirmar o princípio da eficiência significa negar socorro ao mais necessitado ou discriminar certas categorias de indivíduos, o que é injusto e bárbaro. Afirmar princípios de justiça pode, por sua vez, significar que recursos que provavelmente salvariam determinados pacientes serão consumidos por outros sem que resultem para estes últimos em benefícios significativos ou duradouros.

Dilemas entre justiça e eficiência se repetem quando se procura estabelecer prioridades na política de saúde, o que contribui decisivamente para paralisar o debate normativo associado ao que venha a ser uma distribuição mais adequada de recursos no setor. Esta dificuldade em avançar o debate normativo acaba contribuindo também para fragilizar o debate teórico. Afinal, quando se consegue definir onde se quer chegar, deve-se enfrentar imediatamente a questão de como chegar lá, o que estimula o trabalho de investigação sobre quais são, afinal, as variáveis responsáveis pela produção do atual modelo e como se poderia atuar sobre elas no sentido de alcançar uma nova distribuição.

Ora, como em saúde, assim como em muitas outras políticas públicas, são raras as situações em que as opções são claras, acabamos ficando, na maioria das vezes, sem um modelo normativo e, também, sem a possibilidade de aprofundar o debate teórico a respeito de como se produz o perfil de distribuição de recursos no setor. Esta situação tem facilitado a proliferação de estudos que atribuem as distorções na distribuição de recursos à atuação do setor privado, sem explicitar os mecanismos que têm permitido que esses interesses sejam beneficiados.

Nesse contexto, o sistema de atendimento ao doente renal crônico representa uma fonte de pesquisa extremamente estimulante, pois é um desses raros casos em que é 
possível definir uma proxy do que seja uma distribuição adequada de recursos entre os tratamentos disponíveis. Neste caso, existe um consenso entre médicos, doentes e especialistas sobre como distribuir os recursos entre os transplantes e a diálise atendendo simultaneamente às demandas de justiça e eficiência.

Mais ainda, no caso do Sistema Brasileiro de Atendimento ao Doente Renal Crônico, a comparação entre a distribuição ideal e a atual mostra que esta última não só é claramente inadequada como não tem apresentado uma tendência a se aproximar da ideal. E isso apesar das várias políticas empreendidas pelo Ministério da Saúde e secretarias estaduais no sentido de incentivar a atividade transplantadora.

Dadas estas características a existência de um parâmetro objetivo aceito por especialistas e doentes sobre qual é a distribuição adequada de recursos entre os tratamentos disponíveis, a análise desse sistema possibilita uma reflexão sistemática sobre os fatores que têm impedido que se alcance uma distribuição mais adequada, permitindo que se aprofunde o debate teórico em torno dos mecanismos responsáveis pela distribuição de recursos no interior do sistema de saúde e que se teste a adequação das explicações que atribuem aos interesses do setor privado ligado à diálise a responsabilidade por essas distorções.

Temos hoje no Brasil algo em torno de 70 mil doentes renais crônicos, dos quais cerca de 32 mil recebem tratamento a um custo de aproximadamente US $\$ 400$ milhões ao ano, sendo quase $90 \%$ desses tratamentos financiados com recursos públicos. A insuficiência renal crônica é uma doença terminal caso o paciente não receba tratamento imediato e sistemático. Existem dois procedimentos que permitem substituir a função renal natural: o transplante e a diálise. Sendo o transplante uma solução mais econômica, que permite uma boa sobrevida e uma qualidade de vida melhor do que a diálise, é a opção preferida tanto pelos especialistas como pelos pacientes. Apesar disso, em cada cem pacientes renais que hoje recebem tratamento, apenas seis são encaminhados para transplante, quando, segundo estimativas da Sociedade Brasileira de Nefrologia, cerca de 60 destes pacientes estão aptos, de um ponto de vista médico, para realizar a cirurgia.

Esta situação é particularmente intrigante quando se sabe que, se fosse modificada a repartição dos recursos públicos atualmente destinados ao tratamento da insuficiência renal, poder-se-ia não só garantir tratamento a um maior número de doentes, como também lhes permitir uma qualidade de vida melhor. Estes fatos já foram claramente enunciados pela comunidade científica, pelos doentes e pelas agências estatais que cuidam dessas políticas. O perfil de distribuição de recursos entre o transplante e a diálise é, no entanto, cada vez mais desfavorável ao primeiro. Em 1976, quando as duas técnicas ainda eram experimentais, o número de pessoas tratadas por transplante e diálise era semelhante. Já em 1986 foram oferecidos 820 transplantes e 9 mil tratamentos dialíticos, e em 1995 realizaram-se 1.700 transplantes, ao passo que mais de 25 mil pessoas receberam tratamento dialítico.

É importante notar, portanto, que mesmo tendo ocorrido um crescimento considerável da atividade transplantadora, proporcionalmente ela cresceu menos do que a atividade dialítica nas últimas duas décadas. Como se pode observar no Gráfico 1, essa tendência, que já aparecia no final da década de 70, se manteve nas décadas de 80 e 90, apesar de ter crescido, nos últimos 15 anos, o consenso em torno da idéia de que é necessário tanto uma maior integração entre o transplante e a diálise quanto um crescimento mais acentuado da atividade transplantadora, e de ter-se definido, desde 1987, com o Sirc-Trans, $-\underline{1}$ uma política federal para alcançar esses objetivos.

\section{Gráfico 1}

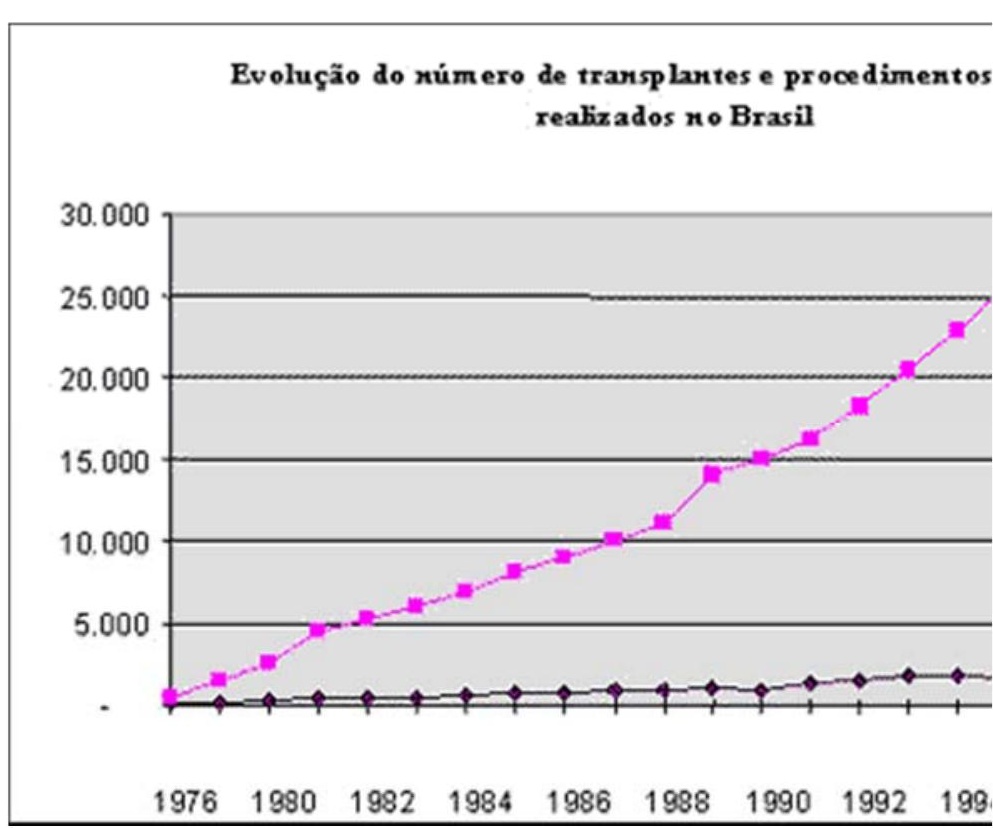

O acentuado crescimento da atividade dialítica, quando comparado ao da atividade transplantadora, é interpretado como decorrente tanto da atuação dos interesses do setor privado ligado à diálise, quanto da falta de recursos financeiros, hospitalares e de órgãos para viabilizar o transplante. Discutirei a seguir a adequação destas explicações.

Explicações correntes: escassez de recursos e interesses privados

Os médicos transplantadores têm argumentado que a insuficiente remuneração paga pelo Sistema Único de Saúde (SUS) pelo transplante é o grande impedimento ao seu crescimento. "Esse procedimento, muito mais complexo e seguramente mais trabalhoso para a equipe 
clínico-cirúrgica, é o que apresenta a menor relação entre honorário médico e custo do procedimento. É consenso entre os nefrologistas que o principal óbice a essa terapêutica decorre da remuneração inadequada do transplante." (Sesso, 1987, p. 52).

Mesmo que se concorde com o argumento de que a baixa remuneração pelo transplante é o principal impedimento ao seu desenvolvimento, deve-se atentar para alguns fatos antes de concluir que o transplante não cresceu por falta de recursos. O primeiro deles é que a expansão na oferta de tratamento para os doentes renais crônicos foi acompanhada, nos últimos 20 anos, por um crescente comprometimento de recursos do orçamento federal no seu financiamento. O segundo é perceber que, dados esses recursos, teria sido possível alocá-los de forma diferente da que foi feita.

O investimento no tratamento da doença passou, nestes 20 anos, de algumas centenas de milhares de dólares ao ano, na década de 70 , para quase US $\$ 400$ milhões na década de 90 . Estima-se que na década de 80 foram gastos cerca de US $\$ 1,5$ bilhão no tratamento da doença, e que entre 1987, ano em que foi criado o Sirc-Trans, e 1996 foram consumidos cerca de US $\$ 3$ bilhões no programa (Sesso, 1990; Coelho, 1996). Teoricamente teria sido possível, portanto, principalmente a partir de meados da década de 80, canalizar para o crescimento da atividade transplantadora uma parte mais significativa dos novos recursos que entraram, a cada ano, no sistema de tratamento dos doentes renais crônicos.

Esse argumento ganha força quando se sabe que, a partir de 1985, algumas novidades tornaram a expansão da atividade transplantadora ainda mais factível. Durante toda a primeira metade da década de 80, países como os Estados Unidos, a Alemanha, a Espanha e os escandinavos haviam experimentado um rápido crescimento em sua atividade transplantadora, crescimento que estava associado à criação e ao desenvolvimento de organizações locais, nacionais e transnacionais de resgate e distribuição de órgãos e ao estímulo representado pelo aumento significativo da sobrevida do enxerto renal, alcançado a partir da utilização em larga escala de drogas como a ciclosporina e o anticorpo monoclonal (OKT3), que contribuem para minimizar a rejeição ao transplante. Essas drogas começaram a ser usadas no Brasil sobretudo a partir de 1985 (Ianhez, 1994).

Quanto à idéia de que a atividade transplantadora foi cerceada pela falta de órgãos, Pestana (1992) e Vaz (1993) mostraram que o brasileiro doa e que, ao menos em tese, haveria quantidade suficiente de órgãos para permitir um significativo crescimento da atividade transplantadora.

Diante dessa situação, os doentes, os médicos sanitaristas, as autoridades sanitárias e os cientistas sociais concluem que são os interesses privados ligados à diálise que têm exercido um papel decisivo no cerceamento da atividade transplantadora: "Efetivamente, um fator que impede o desenvolvimento da política de transplante renal no país é o interesse lucrativo em torno dos tratamentos dialíticos, majoritariamente controlados pela iniciativa privada." (APREC, 1990).

Esse argumento encontra um forte respaldo no fato de que a diálise, uma atividade controlada pelo setor privado, é remunerada de forma muito mais adequada do que o transplante, uma atividade desenvolvida

preponderantemente pelo setor público, em especial pelos hospitais universitários. Para se ter uma idéia mais precisa da questão, vale notar que um tratamento dialítico é remunerado em aproximadamente US $\$ 15$ mil ao ano tanto pelo SUS como por um paciente que pague privadamente pelo procedimento; já um transplante é reembolsado em, no máximo, US\$10 mil pelo SUS, ao passo que um paciente privado paga entre US $\$ 20$ mil e US\$50 mil pela cirurgia.

Essa situação resulta, segundo a visão corrente, de um processo de privatização do Estado que permite que interesses privados dominem os mecanismos de distribuição de recursos, garantindo valores mais altos de remuneração para a diálise mesmo quando, do ponto de vista público, pareceria lógico aumentar o valor do transplante como forma de incentivar a atividade.

Apesar de essa explicação oferecer uma versão plausível sobre por que não se consegue superar distorções gritantes na distribuição de recursos, ela é geralmente enunciada sem que seja feito um trabalho de identificação dos mecanismos que estariam permitindo aos interesses privados se apropriarem dos recursos públicos. Com isso, aspectos importantes do processo de distribuição de recursos permanecem obscuros.

Quando há a preocupação de mostrar como os interesses adentram as instituições e como os recursos são distribuídos através delas, percebemos que, em muitos casos, a capacidade administrativa e as regras de funcionamento dessas instituições desempenharam um papel central tanto na consolidação como no fortalecimento de certos interesses, munindo-os de recursos que eles dificilmente conseguiriam mobilizar valendo-se apenas da sua própria capacidade de organização.

Com vistas a alargar a compreensão dos fatores envolvidos na definição da distribuição de recursos entre o transplante e a diálise, farei, a seguir, uma reconstituição de alguns dos principais momentos na organização do Sistema Brasileiro de Atendimento ao Doente Renal Crônico, discutindo o papel dos interesses vis-à-vis o contexto institucional na determinação do atual perfil de distribuição de recursos entre essas terapias. Confrontar essas duas perspectivas é importante na medida em que cada vez mais se discute a necessidade de estabelecer prioridades na política de saúde que sejam conformes ao interesse público e se buscam alternativas para implementá-las. 


\section{Adotando uma perspectiva neo-institucionalista}

A perspectiva tomada na análise que se segue procura ressaltar a importância das normas de funcionamento e dos procedimentos executados pelo Estado e, mais particularmente, pelas instituições estatais na determinação dos resultados da política de saúde. Dessa perspectiva, estas instituições não são apenas arenas onde os interesses sociais se confrontam, mas são também conjuntos de procedimentos que, ao processarem esses interesses, permitem o uso de certos recursos e excluem outros.

Desse ponto de vista, os resultados de uma política pública passam a depender não apenas da força dos interesses em confronto, mas também da forma como os procedimentos executados no interior dessas agências burocráticas reforçam ou inibem as iniciativas tomadas por diferentes atores. A possibilidade de que o Estado venha a assumir adequadamente novas políticas é, assim, largamente determinada pelas políticas prévias, que criaram certas capacidades administrativas, definiram uma distribuição de recursos, incentivaram alianças e consolidaram procedimentos burocráticos. A própria necessidade de reformas é percebida a partir dos problemas detectados nas políticas existentes e as novas políticas serão construídas sobre programas e estruturas preexistentes.

Isso significa que o processo de discussão de alternativas e tomada de decisão é largamente determinado pelo contexto institucional. As alternativas precisam ser elaboradas, o que se faz em contextos organizados. Nesses contextos, a atenção é direcionada, as alternativas são apresentadas de determinado ângulo, apenas parte das informações está disponível, há participantes comprometidios com certas demandas e a memória institucional é consultada de uma certa maneira (Weir, Orloff e Skocpol, 1988).

Além das regras e procedimentos que organizam o formato institucional, os atores defrontam-se também com um conjunto de capacidades administrativas específicas resultantes de políticas passadas e que vão influenciar o seu comportamento. Essas capacidades desempenham um papel central seja na seleção das propostas que são efetivamente consideradas no interior da burocracia pública, seja na determinação das chances de sucesso dessas propostas uma vez implementadas (Immergut, 1992, p. 23; Orloff, 1993, p. 90).

As mudanças nas instituições e nas políticas públicas são entendidas, a partir daí, não apenas em função da determinação e da força dos diferentes agentes sociais, mas também do contexto institucional em que elas se processam. Contexto que molda e constrange as escolhas dos diferentes atores ao mesmo tempo em que pode fortalecê-los ou debilitá-los em função das suas regras de funcionamento (March e Olsen,1989, p. 56).
Assim, sem desconsiderar a importância, seja do contexto social, seja dos motivos dos atores individuais, devemos passar a atribuir um papel mais independente e central às agências burocráticas que recebem e processam as propostas encaminhadas pela sociedade. Nesse sentido, a ação do Estado não pode ser entendida como simples tradução, no nível político, de pressões externas à sua esfera; deve ser percebida também como função de diferentes graus de autonomia, centralização, burocratização e diferenciação associados à sua estrutura.

Nesse processo, também deve ser levada em conta a experiência que as políticas anteriores legaram aos atores sociais. Nesse sentido, os atores já assistiram ao desenvolvimento de programas sociais, já aderiram a certas propostas, bem como se sentiram frustrados pelos resultados de certas políticas. Ou seja, quando surgem novas propostas, eles as avaliam levando em conta tanto as possibilidades que elas projetam para o futuro como a sua experiência passada (Skocpol, 1992).

Adotando esta perspectiva, analiso o papel desempenhado pelos interesses, pelas políticas prévias e pelas instituições de saúde no desenvolvimento do Sistema Brasileiro de Atendimento ao Doente Renal Crônico, ressaltando o modo pelo qual o contexto institucional tem influenciado a estruturação das demandas, os recursos políticos detidos pelos diferentes atores e o resultado das políticas públicas.

Como já foi dito, o insucesso das repetidas tentativas de tornar o sistema de atendimento aos doentes renais crônicos mais justo e eficiente é interpretado como uma conseqüência tanto da atuação dos interesses ligados à diálise, que se organizaram para drenar a maior quantidade de recursos possível, como da escassez de recursos. A análise desenvolvida a seguir mostra que o perfil de distribuição de recursos públicos entre o transplante e a diálise reflete o ponto de equilíbrio definido pela interação entre interesses e constrangimentos institucionais, econômicos, técnicos e éticos. Uma interpretação adequada das nuanças e dificuldades enfrentadas na política de tratamento dos doentes renais crônicos, bem como das possibilidades de mudança no perfil de distribuição de recursos entre o transplante e a diálise, deve, assim, levar em conta não apenas os atores e interesses em questão, mas também o contexto institucional que permite a expressão desses interesses. Caso contrário as variáveis sociais ficarão divorciadas do contexto político-administrativo que lhes dá sentido. Afinal, nenhuma compreensão da política pode se assentar exclusivamente nas instituições, nos interesses ou nas normas sociais; antes, deve vir da análise integrada desses vários fatores.

\section{O desenvolvimento do Sistema Brasileiro de Atendimento ao Doente Renal Crônico}

Como já foi dito, o tratamento da insuficiência renal terminal crônica começou a ganhar corpo a partir de 1976, 
quando os centros de diálise passaram a receber reembolso da Previdência Social pelos serviços prestados aos pacientes. Nesse período, a diálise cresceu em centros privados de porte médio, que podiam facilmente se credenciar junto ao Instituto Nacional de Assistência Médica e Previdência Social (Inamps), integrando-se, assim, ao seu padrão de prestação de serviços à população previdenciária.

Nos dez anos que se seguiram ao credenciamento dos primeiros centros de diálise, a atividade apresentou uma expansão notável, não só no número de pacientes tratados, que passou de 500 em 1976 para 9 mil em 1986, como também em sua abrangência geográfica. Sem dúvida, a atraente remuneração paga por esses procedimentos, aliada à relativa simplicidade dos processos envolvidos na instalação de uma unidade de diálise e à falta de uma fiscalização mais rigorosa por parte do Inamps, contribuíram para a expansão vigorosa do tratamento dialítico no Brasil.

Já o transplante se desenvolveu muito mais lentamente: passamos de 729 cirurgias em 1976 para 820 em 1986. Esse ritmo pode ser parcialmente explicado pelo fato de o transplante ter crescido sobretudo dentro dos hospitais universitários, que são entidades de ensino e pesquisa que dificilmente podem se especializar em transplantes, uma vez que há sempre um número máximo de leitos destinados a esse procedimento. Vale ainda lembrar que, na época, os hospitais universitários atendiam prioritariamente à população indigente, não recebendo reembolso do Inamps pelo atendimento a esses pacientes.

Acompanhando esta situação, a diretoria da Sociedade Brasileira de Nefrologia já em 1979 alertou para a necessidade de controlar a qualidade e os custos dos tratamentos dialíticos, bem como para o descompasso que já se notava entre o acelerado crescimento das atividades de diálise e o tímido desenvolvimento do transplante. Para sanar esses problemas, propôs, naquele ano, as bases para o estabelecimento de um Programa Nacional de Assistência ao Doente Renal Crônico Terminal. Em linhas gerais, esse programa é até hoje defendido tanto pela Sociedade Brasileira de Nefrologia como pelas associações de pacientes renais crônicos e pelas autoridades sanitárias.

O Inamps, órgão credenciador e pagador dos serviços, era a única instituição que naquele momento detinha os recursos necessários à implementação desse programa, mas pouco fez pelas questões colocadas pela Sociedade Brasileira de Nefrologia. Esse comportamento é compreensível se consideramos que o Inamps era uma instituição mais preparada para promover a expansão da oferta de serviços do que para planejar esta oferta e fiscalizar sua qualidade.

O desinteresse do Inamps pela idéia de um sistema que integrasse os dois principais tipos de tratamento oferecidos ao doente renal crônico fez com que desde logo prevalecessem os projetos individuais dos prestadores de serviços, que em muitos casos se caracterizavam como empreitadas empresariais pouco comprometidas com a qualidade dos serviços prestados. Além disso, a relação contratual existente não permitia uma supervisão direta das ações contratadas pelo Inamps, o qual, por sua vez, não estruturou um sistema de informações que permitisse maior controle sobre os gastos, o crescimento e a qualidade do setor. Entende-se, assim, por que foi tão reduzida a capacidade do Instituto em orientar de forma mais adequada a extraordinária expansão da oferta de tratamentos para a insuficiência renal terminal crônica.

É importante frisar o importante papel que o Inamps, com suas características (grande preocupação com a expansão da oferta de serviços e pouca atenção ao planejamento), desempenhou na criação de um robusto parque dialítico. Essas características, aliadas àquelas da diálise (relativa simplicidade dos procedimentos e portabilidade dos equipamentos), garantiram o enraizamento por todo o território nacional de uma rede de interesses privados ligados à atividade.

Esses interesses conseguiram, a partir de então, se organizar e continuar crescendo, mesmo em situações adversas, como a vivida em 1983, quando o Ministério da Previdência, tendo em vista o agravamento da crise econômica iniciada no final da década de 70 , foi pressionado a comprimir as despesas e o Inamps decidiu restringir os gastos reduzindo os valores pagos pelo tratamento dialítico. Nesse contexto, a Sociedade Brasileira de Nefrologia reagiu vigorosamente contra tais reduções: enviou por inúmeras vezes representantes a Brasília para falar com os dirigentes do Inamps, criou um fundo para financiamento das despesas e, finalmente, se associou à Federação dos Hospitais, sancionando proposta desta última no sentido de devolver ao Inamps os pacientes em diálise caso não se alcançasse um acordo sobre o valor pago pelas sessões de hemodiálise. A crise durou quase um ano e só se resolveu quando, finalmente, a Sociedade Brasileira de Nefrologia conseguiu "uma solução que está de acordo com os anseios dos nefrologistas brasileiros", isto é, uma solução que repõe os valores anteriormente pagos pelas sessões de hemodiálise (Jornal Brasileiro de Nefrologia, 1983 e 1984).

Ora, é notável a diferença entre a capacidade de mobilização e os resultados alcançados pela Sociedade ao procurar incentivar o transplante e ao defender os valores de remuneração da diálise. A remuneração para o transplante não era menos aviltante do que a proposta para a diálise, mas ela nunca conseguiu mobilizar nenhuma reação comparável à acima descrita. Esse exemplo mostra como a diálise ganhou uma enorme vantagem sobre o transplante por ter sido desde o início bem remunerada. Isto porque é mais fácil mobilizar interesses para garantir ganhos já incorporados do que organizá-los para obter novos ganhos.

Nesse sentido, quando se pensa na força dos interesses ligados à diálise, deve-se entender que ela decorre em grande parte da política seguida pelo Inamps, que, ao assegurar à diálise uma remuneração atraente, permitiu, já na década de 70, que este tratamento crescesse mais do 
que o transplante. Com isso, o Inamps acabou comprometendo decisivamente as possibilidades futuras de organização de um sistema integrado de tratamento da doença renal, uma vez que todas as propostas que surgiram na década de 80 encontraram um "sistema" de tratamento já constituído, no qual o transplante se enraizara nos hospitais universitários, a diálise se expandira por todo o país como um empreendimento médico de médio porte, e a autonomia tanto das equipes transplantadoras quanto das de diálise era enorme, enquanto a integração entre elas era muito pequena.

\section{O projeto do sistema integrado de tratamento da} insuficiência renal crônica

\section{Iniciativas da esfera federal}

A organização precoce do sistema de diálise não é, entretanto, uma particularidade brasileira. Em outros países onde havia disponibilidade de recursos e grande demanda por tratamento também se organizou um sólido parque dialítico, sem que isso chegasse a impedir que o transplante crescesse a taxas maiores que a diálise a partir da década de $80 . \underline{2}$

A criação do Sirc-Trans, em 1987, representou a primeira tentativa de definir uma política federal global para atender os doentes renais crônicos e incluir o Brasil no rol dos países transplantadores. Tanto o Sirc-Trans quanto o Sipac-Rim, que o substituiu a partir de 1990, indicaram o transplante como "a melhor opção de tratamento da insuficiência renal crônica" e definiram o sistema integrado de tratamento como o objetivo da política federal para o setor. Isso não foi suficiente, no entanto, para garantir um maior controle sobre a diálise, ou a organização de um sistema integrado de tratamento da insuficiência renal crônica. Em 1991 o Sipac-Rim se autodissolveu.

Se a criação do Sirc-Trans pode ser identificada como parte de um movimento internacional de valorização da atividade transplantadora, deve ser entendida também como parte das grandes transformações por que passou o sistema de saúde brasileiro ao longo dos anos 80, no sentido de sua descentralização, e que resultaram na implementação, em 1987, do Sistema Unificado e Descentralizado de Saúde (SUDS) e na criação, em 1988, do Sistema Único de Saúde (SUS).

Contudo, embora a idéia de um sistema integrado de tratamento da doença renal crônica fosse muito bemvinda, as regras de financiamento do SUDS e do SUS representaram um obstáculo totalmente imprevisto e, aliás, só tardiamente identificado ao seu desenvolvimento. Segundo essas regras, montantes fixos de recursos, calculados a partir de parâmetros definidos oficialmente, eram destinados aos procedimentos ambulatoriais e aos hospitalares. Uma vez calculados esses montantes, os recursos referentes aos procedimentos ambulatoriais, dentre os quais a diálise, eram repassados para as secretarias estaduais, ao passo que os recursos destinados aos procedimentos hospitalares, dentre eles o transplante, permaneciam na esfera federal. Essa divisão explica o controle que o Sirc-Trans e o Sipac-Rim conseguiram exercer sobre a atividade transplantadora, já que nessa área os pagamentos eram feitos pela esfera federal, o que permitiu condicionar o pagamento dos serviços à prestação de contas e ao envio de informações. Já o objetivo de organizar um sistema integrado de tratamento era muito mais difícil de ser alcançado pela esfera federal, uma vez que as secretarias estaduais de Saúde é que eram responsáveis pelo pagamento dos procedimentos ambulatoriais, bem como pelo seu controle. Com isso, os dialisadores nunca se submeteram às diretrizes seja do Sirc-Trans, seja do Sipac-Rim, ou lhes enviaram qualquer informação.

Ora, um sistema integrado depende tanto da integração entre os prestadores como de um orçamento único a partir do qual se possa incentivar as mudanças desejadas na distribuição de recursos entre o transplante e a diálise. Naquela situação, um orçamento integrado não só era difícil de ser concretizado como não foi sequer cogitado. O sistema não contava, como até hoje não conta, com mecanismos simples de realocação de recursos de um procedimento ambulatorial para um procedimento hospitalar, não oferecendo, portanto, incentivos para que os atores envolvidos no processo buscassem otimizar a distribuição de recursos entre o transplante e a diálise.

Naquele contexto, nada do que fosse economizado com a diálise iria para o transplante. Tanto do ponto de vista dos pacientes, como dos nefrologistas ou da indústria, deixar a situação como estava significava manter o volume de recursos investidos no setor. É extremamente importante perceber como uma regra de financiamento do sistema de saúde levou os atores a optarem, na prática, por um comportamento de reforço do padrão existente, mesmo quando esse padrão não correspondia a seu projeto.

Outro problema associado à forma de financiamento do sistema é que, mesmo nos momentos em que se conseguiu melhorar a remuneração para o transplante, não houve como diferenciar o valor de uma consulta para atender um paciente no pós-transplante das demais consultas pagas pelo SUS. Com isso, os baixos valores pagos pelas consultas se constituíram em mais um obstáculo à ampliação da atividade transplantadora, já que o hospital que realizava o transplante ficava responsável pelo paciente mas não recebia praticamente nada por esse acompanhamento clínico. Dessa forma, incentivava-se o prestador de serviços a oferecer tratamentos dialíticos, que eram pagos integralmente, e reiterava-se uma situação em que ele era levado a oferecer os serviços que, para o sistema de saúde, eram os mais caros.

Em 1993 foi criada a Coordenação de Procedimentos de Alta Complexidade do Ministério da Saúde, que definiu o transplante de órgãos como um procedimento de alta complexidade. $\underline{3}$ Nesse mesmo ano, a Sociedade Brasileira de Nefrologia voltou a pressionar o Ministério no sentido 
de retomar o projeto de um sistema integrado de tratamento do doente renal crônico. Dessa negociação resultou a Portaria 38, que, a partir de março de 1994, passou a normatizar o sistema de atenção ao doente renal crônico. Apesar de essas iniciativas manterem alguns dos objetivos do Sipac-Rim, como a produção de informação, o controle de qualidade e, no caso da Portaria 38, a integração entre os serviços de diálise e transplante, elas alcançaram pouco sucesso. 4

A inexistência de mecanismos que permitissem integrar os recursos disponíveis para o tratamento da insuficiência renal crônica e alocá-los segundo uma lógica própria a um sistema integrado de tratamento é um dos fatores que explica a falta de impacto das políticas federais que sempre recomendaram o incentivo ao transplante sobre a relação entre o número de transplantes e procedimentos de diálise realizados no período. Assim, apesar de várias iniciativas do Ministério da Saúde terem como um de seus principais objetivos o incremento da proporção de transplantados, a relação entre o número de transplantes e tratamentos dialíticos oferecidos, que era de $8 \%$ em 1981, chegou a $6 \%$ em 1995 , como se pode observar no Gráfico 2. Na leitura desse gráfico é preciso lembrar que, até 1976, tanto a diálise como o transplante eram terapias experimentais. Em 1976, quando o Inamps passou a reembolsar generosamente pelos serviços de diálise, ocorreu uma rápida expansão na sua oferta. Esse fato explica a expressiva queda, de $0,39 \%$ para $0,09 \%$, na relação analisada entre 1976 e 1981.

\section{Gráfico 2}

Relaçio entre o número de transplantes e dialiticos realix ados no Brasil -1

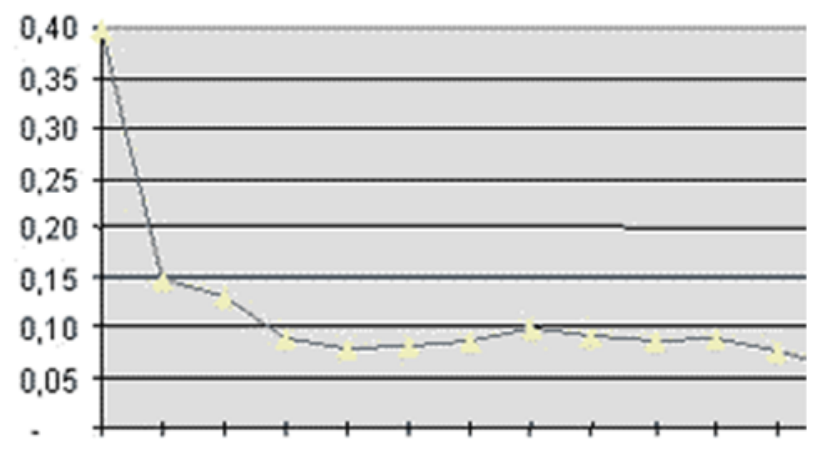

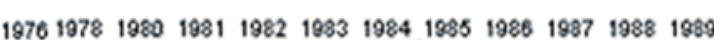

Essa situação mostra com muita nitidez como os atores tiveram suas posições fortalecidas ou debilitadas em função das regras de financiamento do sistema de saúde, a partir de uma lógica que nada tinha a ver com a coerência dos projetos que defendiam. Essas regras contribuíram para diminuir consideravelmente as possibilidades de sucesso das políticas propostas pelo Sirc-Trans e pelo
Sipac-Rim. Ou seja, uma regra de financiamento tornou vazia, do ponto de vista prático, a proposição de priorizar o transplante e deu à diálise uma autonomia que os próprios interesses ligados a ela teriam dificuldade em garantir em um contexto altamente favorável à expansão da atividade transplantadora.

\section{Iniciativas estaduais}

Como já foi apontado, o crescimento da atividade transplantadora experimentado por países como os Estados Unidos, a Alemanha e a Espanha esteve associado à criação e ao desenvolvimento de organizações locais, nacionais e transnacionais de resgate e distribuição de órgãos. No Brasil, embora alguns estados como Minas Gerais, Rio de Janeiro, Rio Grande do Sul e São Paulo tenham buscado organizar sistemas estaduais de transplantes baseados em um alto grau de integração interinstitucional, pode-se dizer que poucas foram as experiências bem-sucedidas. O mais comum até hoje é a atuação independente dos centros de diálise e a organização independente de cada equipe de transplante para o resgate e a alocação de órgãos.

O caso do Estado de São Paulo ilustra bem as dificuldades em se alcançar esta integração. Em 1987, o estado parecia contar com as condições necessárias ao sucesso de um sistema estadual de transplante. Com a descentralização, recursos consideráveis foram transferidos para a Secretaria de Estado de Saúde (SES), que passara a pouco tempo por uma reforma administrativa e parecia estruturalmente apta a implantar um sistema estadual de saúde. A questão renal estava incluída em sua agenda, como revelam as iniciativas do Grupo Especial de Programa (Gepro) de Doenças Crônico-Degenerativas e a Constituição estadual, que incentivava a criação de uma Central de Resgate de Órgãos no estado.

Naquele período, o Estado de São Paulo concentrava aproximadamente $50 \%$ dos transplantes de rim do país, estando as principais equipes transplantadoras sediadas em hospitais universitários. Estas dispunham de grande autonomia, definindo seus protocolos e critérios de distribuição de órgãos, gerindo suas listas de espera e incentivando o transplante com doador-cadáver. Tais equipes, junto com as de transplante cardíaco e de córnea, participaram do processo de discussão para a criação da Central de Resgate de Órgãos, cuja pauta inicial refletiu bem o espírito daqueles tempos, quando tudo parecia possível: a integração entre as equipes médicas, a democratização das listas de espera, a tipagem HLA, $\underline{5}$ a agilidade da Secretaria em gerir esse sistema. A mobilização desse período aparece, também, no fato de todas as equipes de transplante terem, em maior ou menor grau, discutido e se posicionado sobre a proposta de organizar um sistema estadual de transplante de rim. Discutiram-se temas ligados à centralização do resgate e da distribuição de órgãos, aos critérios de distribuição e ao trade-off entre justiça e eficiência.

Esse cenário propiciou um novo momento no debate sobre a organização do sistema de transplante e um 
espaço para a negociação entre os vários atores ligados ao problema. A primeira grande aposta foi criar um sistema estadual de transplante, o que requeria um alto grau de integração entre as equipes transplantadoras, além de uma terceira parte capaz de fazer a mediação entre os interesses das equipes e os dos doentes. Imaginou-se, como é natural, que caberia ao poder público e, portanto, à Secretaria de Estado da Saúde fazer essa mediação.

Entre 1988 e 1990 foi ficando claro que as condições tanto para a integração entre as equipes médicas como para que a Secretaria fizesse essa mediação não estavam de todo garantidas. O projeto da Central foi debilitado pela resistência que o Inamps impôs ao avanço do SUDS e pela retração de recursos que isso representou, pela falta de agilidade administrativa da SES para sustentar uma política estadual de saúde e, ainda, pela defesa que as equipes transplantadoras fizeram da sua própria autonomia.

Percebe-se, assim, as dificuldades de alcançar a integração interinstitucionalfator importante no processo de constituição de sistemas regionais, que depende de fatores complexos, envolvendo não só a disponibilidade de uma série de recursos materiais leitos de UTI, equipes e aparelhos para diagnóstico de morte cerebral, sistemas de comunicação etc., como também o cálculo que os diferentes atores fazem quanto à possibilidade de que a integração melhore a sua posição.

Nesse contexto, é razoável pensar que o projeto de um sistema estadual de transplante tenha parecido pouco atraente aos transplantadores. Afinal, naquele momento a Secretaria não só era parte de um setor público fragilizado e inconstante, como ela própria não parecia dispor de recursos que lhe permitissem sustentar as funções de planejamento, avaliação e controle, essenciais ao sucesso do Sistema Único de Saúde, bem como as funções de resgate e distribuição de órgãos a que se candidatava.

A percepção que os atores mais fortes ligados à questão renal tinham da fragilidade das instituições públicas ligadas à administração da política de saúde reforçou a sua resistência em participar de iniciativas que, além de envolverem ativamente o poder público, implicavam perda de parte da sua autonomia. No Estado de São Paulo, ficou claro que mesmo os grupos que apoiavam a criação de um sistema centralizado de distribuição de órgãos tenderam a recuar diante da definição de que esse sistema seria gerido pela Secretaria de Saúde, uma vez que entregar a esta a coordenação do resgate e da distribuição dos órgãos poderia ser um fator de desorganização das equipes, que já operavam de forma auto-suficiente.

A experiência brasileira mostra, no entanto, que mesmo em condições adversas a integração interinstitucional pode ser alcançada. Assim, com a progressiva regionalização da política de saúde, vem-se ampliando o número de sistemas estaduais de transplante que procuram coordenar o trabalho das equipes, seja para o resgate de órgãos, seja, em menor número de casos, para centralizar a distribuição dos órgãos captados (Neumann e Kalil, 1989).
Esses sistemas, entretanto, ainda são raros. No Estado de São Paulo já se definiram as instituições necessárias à organização de um sistema integrado de tratamento da insuficiência renal terminal crônica, como o comprova a existência da Central de Resgate de Órgãos, da lista única, do Disque-diálise, da Comissão Estadual de Nefrologia, da Associação Paulista de Renais Crônicos, da Sociedade Brasileira de Nefrologia, da Sociedade Brasileira de Transplante de Órgãos e a experiência do São Paulo Interior Transplantes. $\underline{6}$ Em torno destas instituições gravitam aproximadamente 11 mil pacientes que recebem tratamento, cem centros de diálise e 23 equipes de transplante que movimentam algo em torno de US $\$ 130$ milhões por ano, e ainda assim não se conseguiu avançar muito no sentido de concretizar uma ação coordenada que favoreça um tratamento integrado da questão.

A dificuldade em alcançar uma maior integração entre as instituições que trabalham no tratamento da insuficiência renal terminal crônica pode ser explicada pelas relações que se estabelecem entre o setor estatal e o privado, pelo grande poder discricionário dos médicos, pela sua pequena vulnerabilidade a ações litigiosas e pela fragilidade administrativa do Estado. Em um sistema em que os médicos são mais vulneráveis ao litígio ou em que o Estado aparece como um parceiro forte, aceitam-se mais facilmente arranjos que restringem o poder discricionário das equipes médicas. Nessas situações, são maiores as chances de que as preferências se orientem para sistemas mecânicos de alocação de órgãos baseados em critérios objetivos como a tipagem HLA e o tempo de espera em lista, administrados pelo poder público ou por sociedades de especialistas.

\section{Conclusão}

Em 1996 eram oferecidos no Brasil cerca de 25 mil tratamentos dialíticos e 2 mil transplantes ao ano, enquanto 5 mil pessoas viviam com um rim transplantado. O programa consumia anualmente quase US $\$ 400$ milhões, sendo US $\$ 350$ milhões financiados pelo SUS. Pode-se estimar que nos últimos dez anos foram gastos cerca de US\$3 bilhões com o programa. Ainda assim, mais da metade dos aproximadamente 70 mil doentes renais crônicos permanecem sem tratamento.

Os recursos investidos no Sistema Brasileiro de Atendimento ao Doente Renal Crônico mostram que a alegada escassez de verbas destinadas à expansão da atividade transplantadora deve ser discutida no contexto global do financiamento desse sistema. Dessa perspectiva, fica claro que uma massa significativa e crescente de recursos públicos vem sendo alocada para o tratamento da insuficiência renal crônica e que caberia às instituições responsáveis pela compra desses serviços, isto é, o Inamps, o SUDS e o SUS, terem garantido uma estratégia de compra que permitisse adquirir, com a mesma quantidade de recursos, um volume maior de procedimentos para atender a mais doentes, oferecendolhes, ainda, melhor qualidade de vida. 
Os que têm procurado entender por que essas intituições não conseguiram caminhar nesse sentido vêm sugerindo que as instituições públicas responsáveis pela administração da política de saúde foram capturadas pelos interesses privados ligados à diálise. A história aqui reconstituída sugere algo diferente, apontando para a importância dos fatores institucionais na determinação destes resultados. Com isso, indica o limite de teorias que interpretam o conteúdo e o resultado das políticas públicas como um reflexo direto da força e dos interesses dos atores em disputa e corrobora conclusões alcançadas anteriormente por outros estudos que apontam a importância das políticas prévias e do desenho institucional na determinação desses resultados (Heclo, 1974; March e Olsen, 1989; Weir, Orloff e Skocpol, 1988; Immergut, 1992; Weaver e Rockman, 1993).

Nesse sentido, o primeiro ponto a ser notado é que os interesses ligados à diálise foram em grande medida constituídos a partir da atuação do Inamps, que incentivou a rápida expansão da atividade dialítica no Brasil. Ou seja, um certo tipo de política de saúde fomentou o crescimento de um certo tipo de empresário de saúde, o que mostra que "da mesma forma que a política cria as políticas públicas, estas também recriam a política" (Skocpol, 1992, p. 58).

O tratamento dialítico começou a ganhar espaço a partir de meados da década de 70, quando o Inamps passou a credenciar unidades de hemodiálise que a partir de então se disseminaram por todo o país. Esta iniciativa do Inamps deve ser entendida no contexto de uma forte demanda dos doentes renais crônicos por tratamento e das características da diálise (isto é, a relativa simplicidade dos procedimentos e a portabilidade dos equipamentos), que permitiam uma rápida expansão da oferta desse tipo de tratamento. $\mathrm{O}$ fato de o Inamps estar mais preparado para lidar com pequenas unidades privadas prestadoras de serviço do que para planejar uma política de saúde custoefetiva também contribuiu para reforçar a opção pela diálise.

Ao permitir o rápido crescimento da diálise, o Inamps promoveu a cristalização de uma massa de interesses que, desde o início da década de 80 , tem se mobilizado com sucesso para preservar os níveis de remuneração da atividade e, com isso, garantir a sua contínua expansão. ${ }^{?}$

Um segundo ponto a ser notado é que quando o SUDS e o SUS procuraram rever a política de saúde e a estrutura de incentivos que garantia ao setor privado ligado à diálise a parte do leão na distribuição dos recursos públicos, esbarraram em um aparato institucional que, ao organizar o financiamento do sistema, protegia de forma praticamente automática esses interesses, criando uma inércia difícil de ser vencida.

A política federal de incentivo ao transplante esbarrou em regras que definiam montantes fixos a serem destinados para a compra de procedimentos ambulatoriais e hospitalares e a forma de pagamento desses serviços, descentralizada no caso dos procedimentos ambulatoriais e centralizada no caso dos hospitalares. Essas regras representaram um obstáculo concreto e quase intransponível a qualquer projeto de desenvolvimento de um sistema integrado de tratamento da insuficiência renal terminal crônica.

Dadas essas regras de financiamento e a enorme demanda reprimida por tratamento existente, pode-se dizer que a diálise nunca chegou a disputar recursos com o transplante. Ou seja, a estrutura adminstrativa vigente, até pelo menos meados da década de 90 , fez com que o transplante e a diálise nunca chegassem a competir pelos mesmos recursos. Afinal, essa estrutura garantia que nada do que fosse para o transplante estivesse sendo retirado da diálise.

Um terceiro ponto que deve ser levado em conta diz respeito à dificuldade experimentada para se levar adiante um projeto de integração interinstitucional entre os diversos prestadores de serviço e entre eles e o setor público. Esse projeto, defendido em diferentes situações tanto pelas associações de doentes quanto por médicos e técnicos do governo, perdeu muito de sua força devido à fragilidade vivida desde o início do processo de descentralização e que persiste até hoje pelas instituições estaduais responsáveis pela política de saúde. A percepção que as equipes transplantadoras tinham desta fragilidade de que no caso de a Secretaria de Saúde vir a se responsabilizar pelas atividades de resgate e distribuição de órgãos ela poderia, no limite, levar à desestruturação destas equipes foi decisiva, como vimos, para bloquear o projeto da Central de Resgate e Distribuição de Órgãos no Estado de São Paulo.

Visto deste ângulo, percebe-se como os argumentos que procuram explicar as distorções no sistema de atendimento aos doentes renais crônicos como sendo o resultado, ou da escassez de recursos, ou da força dos interesses privados ligados à diálise, não conseguem explicar toda a história. Se, nesse momento, nos perguntarmos como é possível explicar a estabilidade das taxas que relacionam o número de transplantes e o de tratamentos dialíticos oferecidos, mesmo em um contexto francamente favorável à expansão da atividade transplantadora, seremos levados a reconhecer que, além dos interesses, também as políticas prévias e as instituiçõesque com suas regras, procedimentos normativos e capacidades administrativas acabam fortalecendo certos atores, enquanto fragilizam outros contribuíram para esse resultado.

Com isso, a perspectiva analítica aqui adotada mostra que o resultado da política reflete o ponto de equilíbrio definido pela interação entre interesses e constrangimentos institucionais, econômicos, técnicos e éticos. Afinal, esse caso sugere que os interesses não chegariam a produzir os mesmos efeitos sem estas instituições, bem como que a ação de um mesmo conjunto de interesses poderia, se processada por instituições organizadas de forma diversa, ter levado a resultados diferentes. 
Do ponto de vista daqueles que estão preocupados com a formulação de políticas de saúde que possam atender melhor as demandas de justiça e eficiência, a vantagem desse tipo de análise sobre aquelas que atribuem a ineficácia das políticas públicas apenas aos interesses que bloqueiam soluções socialmente mais adequadas ou à escassez de recursos é chamar a atenção para a importância de se levar em conta os aspectos institucionais tanto na análise como no próprio processo de formulação de políticas para o setor.

\section{NOTAS}

1 O Sirc-Trans foi uma câmara técnica criada para assessorar o Inamps em questões relativas à insuficiência renal terminal crônica.

2 Para se ter uma idéia comparativa, os países escandinavos chegam a tratar 2,3 vezes mais doentes por transplante do que por diálise. $\mathrm{Na}$ Inglaterra, a taxa que relaciona transplantes a tratamentos dialíticos é de 0,8 ; nos EUA essa taxa é de 0,33 , ao passo que no Chile é de 0,08 e no Brasil é de 0,06.

$\underline{3}$ Esta Coordenação foi criada após a autodissolução do Sipac-Rim, em 1991, e a dissolução da Divisão Nacional de Procedimentos de Alta Complexidade, em 1992.

4 A tragédia de Caruaru, em 1996, expôs dramaticamente a situação do sistema, sobretudo a sua falta de fiscalização e a precariedade das informações disponíveis.

5 A tipagem HLA permite a identificação de certas características do sistema imunogenético, que controla a cadeia de reação imunológica. A tipagem é considerada um bom critério para a seleção de pacientes a serem transplantados na medida em que pode ser aplicada objetivamente e permite melhorar o prognóstico do transplante.

6 O São Paulo Interior Transplantes (SPIT) é uma organização não-governamental sediada no Hospital das Clínicas da USP de Ribeirão Preto que atende a uma grande região do interior do estado. Atua como um sistema de distribuição de órgãos para transplante, utilizando-se de procedimentos mecânicos. Dentre os critérios de distribuição por ele utilizados está a tipagem HLA. Mais informações sobre o SPIT podem ser encontradas em Ferraz (1991).

I O nível de serviços públicos que serão financiados na área de saúde é calculado tomando-se por base o comportamento histórico do setor ajustado pelo crescimento demográfico. Nesse contexto, de permanente expansão do teto, a atraente remuneração paga pelos procedimentos dialíticos garantiu o interesse dos prestadores de serviço em expandir a oferta.

\section{BIBLIOGRAFIA}

ABTO Associação Brasileira de Transplantes de Órgãos. (1990), Transplantes renais no Brasil. Comitê de Coleta de Dados. Mimeo.

órgãos. Mimeo.

(1995), Censo nacional de transplante de

APREC Associação dos Pacientes Renais Crônicos. (1990), "Uma campanha e tanto". Boletim do rim, 1, dezembro.

BAXTER HOSPITALAR. (1996), Dados sobre diálise no Brasil. Mimeo.

COELHO, Vera Schattan P. (1996), Interesses e instituições na politica de saúde: o transplante e a diálise no Brasil. Tese de doutorado, Campinas, IFCH/Unicamp.

FERRAZ, Agenor Spallini et al. (1991), "The experience of the 'São Paulo Interior Transplantes' with a multifactorial system for selection of cadaver kidney recipients". Transplantation Proceedings, 23, 5: 2.676-2.677.

HECLO, Hugh. (1974), Modern social politics in Britain and Sweden. New Haven, Yale University Press.

IANHEZ, Luiz Estevam. (1994), "Transplante renal no Brasil: história, evolução e problemas atuais". Jornal Brasileiro de Nefrologia, 16,1: 5-16.

IMMERGUT, Ellen M. (1992), Health politics. Cambridge, Cambridge University Press.

JORNAL BRASILEIRO DE NEFROLOGIA. (1983), "Programas de diálise: nossa luta". Jornal Brasileiro de Nefrologia, 5, 4, novembro.

(1984), "Programas de diálise: nossa luta II", Jornal Brasileiro de Nefrologia, 6, 2, maio.

MARCH, James G. e OLSEN, J. P. (1989), Rediscovering institutions. Nova York, The Free Press.

NEUMANN, Jorge e KALIL, Jorge. (1989),

"Desenvolvimento dos transplantes renais no

Brasil". Jornal Brasileiro de Nefrologia, 11, 3: 71-75

ORLOFF, Ann S. (1993), The politics of pensions. England. The University of Wisconsin Press.

PESTANA, José Osmar Medina et al. (1992), "Estimativa do número de potenciais doadores de órgão na cidade de São Paulo". Revista da Associação Médica Brasileira, 38, 2: $97-$ 100. 
SESSO, Ricardo et al. (1987), "Qualidade de vida dos pacientes com insuficiência renal crônica terminal". Jornal Brasileiro de Nefrologia, 9, 2: 24-28.

. (1990), "Survival analysis of 1.563 renal transplants in Brazil: report of the Brazilian registry of renal transplantation". Nephrology Dialysis Transplantation, 5: 956-961.

(1994), "Aspectos epidemiológicos do tratamento dialítico na Grande São Paulo". Revista da Associação Médica Brasileira, 40, 1: 10-14.

(1995), "Tratamento dialítico do paciente

renal crônico". Revista da Associação Médica Brasileira, 41, 1: $1-2$.

SKOCPOL, Theda. (1992), Protecting soldiers and mothers. Cambridge, Mass., Harvard University Press.

SOCIEDADE BRASILEIRA DE NEFROLOGIA.

Comissão de Diálise e Transplante. (1979)," Tratamento do paciente renal crônico terminal no Brasil". Jornal Brasileiro de Nefrologia, 1, 2, agosto.

Comissão de Diálise e Transplante. (1982), "Terceiro relatório do registro brasileiro de diálise e transplante". Jornal Brasileiro de Nefrologia, 4: 95-98.

Comissão de Diálise e Transplante. (1984), "Relatório final referente ao ano de 1983". Jornal Brasileiro de Nefrologia, 6: 89-96.

VAZ, Maria Lúcia dos Santos. (1993), Estudo da necessidade de transplante de órgãos no Brasil e a disponibilidade de doadores. Tese de doutorado, São Paulo, Escola Paulista de Medicina.

WEAVER, R.K. e ROCKMAN, B.A. (1993), Do institutions matter? Washington, DC, The Brookings Institution.

WEIR, Margaret, ORLOFF, Ann Shola e SKOCPOL, Theda. (1988), The politics of social policy in the United States. Princeton, Princeton University Press.

* Este artigo apresenta resultados de minha tese de doutorado Interesses e instituiçoes na politica de saúde: 0 transplante e a diálise no Brasil, defendida no Instituto de Filosofia e Ciências Humanas da Unicamp em 1996, pesquisa que contou com o apoio do CNPq e da FAPESP, bem como do projeto Justiça local, coordenado pela professora Argelina Figueiredo no Núcleo de Estudos de Políticas Públicas (NEPP) da Unicamp, também apoiado pela FAPESP. Agradeço os comentários feitos pela banca examinadora da tese, composta pelos doutores Agenor Ferraz, Luiz Antonio de Castro Santos, Maria Helena Augusto e Sonia Draibe. Agradeço também os comentários de Argelina Figueiredo, que orientou a tese, e dos pareceristas da RBCS. 